\section{A BASIC program for metaanalysis using Stouffer's formula}

\section{BRIAN MULLEN \\ North Central College, Naperville, Illinois 60566}

The BASIC program described here allows the user to perform a metaanalysis, combining the results of independent studies for the purpose of integrating their findings. Metaanalytic statistics provide a single set of numbers describing the results of a body of research. The included studies may share a common conceptual hypothesis or they may share operations for the realization of specific independent variables or dependent variables regardless of initial conceptual focus. Metaanalysis has recently been applied to reviews of research on sex differences in conformity (Cooper, 1979), the effectiveness of attention and rejection coping styles (Mullen \& Suls, 1982), the influence of interpersonal expectations on behavior (Rosenthal, 1978), and psychotherapy outcomes (Smith \& Glass, 1977). Although this statistical approach to reviewing previous research provides a valuable alternative to an intuitive, literary review, users should realize that the value of a metaanalysis depends upon the methodological soundness and the representativeness of the studies included in the metaanalysis. Stouffer's (1949) method requires that probability levels from included studies are first transformed into $\mathrm{z}$ scores (standard normal deviates), which are then weighted by some factor and related to the number of studies involved (for computational procedures, cf. Cooper, 1979; Glass, 1976; Rosenthal, 1978; Rosenthal \& Hall, 1981).

Input. The program prompts the user to enter a one-tailed $p$ value for each study. Note that one-tailed $p$ values are always less than .50 when results are in the "expected direction" (i.e., when results support the hypothesis under consideration); however, one-tailed $\mathrm{p}$ values are always greater than .50 when results are in the "unexpected direction" (i.e., when results are inconsistent with the hypothesis under consideration). Reported two-tailed $\mathrm{p}$ values supporting the hypothesis under consideration should be halved before entering into the program. Reported two-tailed $p$ values inconsistent with the hypothesis under consideration should be halved and then subtracted from 1.00 before they are entered into the program.

The program also prompts the user to enter a weight for each study. The entered weight could simply be a " 1 " for each study (resulting in an unweighted Stouffer's method of metaanalysis). Alternatively, the entered weight could be any desirable positive attribute (resulting in a weighted Stouffer's method of metaanalysis). Examples of weighting variables are the sample size, the relevant degrees of freedom, or some index of the internal or ecological validity of each study.

When the user has entered all of the $p$ values and all of the weights for each study, he or she enters a " 9 " for the next $p$ value, and the metaanalysis statistics are then calculated and displayed.

Output. The program outputs the retrieved z score after the $p$ value and weight for each study are entered. When the user signals the end of input, the program outputs three related metaanalytic statistics. The standard normal deviate for metaanalysis $\left(Z_{\mathrm{ma}}\right)$ and the probability associated with this standard normal deviate describe the likelihood that the results of the included studies were generated by chance. The fail-safe number for the .05 level of significance $\left(\mathrm{N}_{\mathrm{fs} .05}\right)$ estimates the number of additional studies that failed to reject a null hypothesis of no difference/no effect that would be needed to disconfirm the conclusion derived from the metaanalysis.

Limitations. The $\mathrm{z}$ scores estimated from the entered one-tailed $p$ values are generally accurate to within \pm .009 of the $z$-score values retrieved by hand from any table of probabilities associated with observed values of $z$ in the normal distribution. Extreme $z$ scores (i.e., those associated with $p$ values less than .001 ) are conservatively estimated. Application of this program to the demonstration data listed in Rosenthal (1978, Table 1) essentially reproduces the unweighted $Z_{\mathrm{ma}}$, the weighted $Z_{\mathrm{ma}}$, and the associated $\mathrm{p}$ values reported therein.

Language. The program takes up less than 1,400 bytes of memory and consists of 31 lines. The program is written in Radio Shack Level II BASIC and can be readily translated into other versions of BASIC.

Availability. A program listing is available free of charge from Brian Mullen, Department of Psychology, North Central College, Naperville, Illinois 60566.

\section{REFERENCES}

CoOPE R, H. M. Statistically combining independent studies. Journal of Personality and Social Psychology, 1979, 37, 131146.

Glass, G. V. Primary, secondary and meta-analysis research. Educational Research, 1976, 5, 3-8.

MuLren, B., \& SuLs, J. The effectiveness of attention and rejection es coping styles: A meta-analyzis of temporal differences. Journal of Psychosomatic Research, 1982, 26, 43-49.

Rosenthal, R. Combining results of independent studies. Psychological Bulletin, 1978, 85, 185-193.

Rosenthal, R., \& Hall, J. Critical values of $Z$ for combining independent probabilities. Replications in Social Psychology, $1981,1,1-6$.

Smith, M. L., \& GLAss, G. V. Meta-analysis of psychotherapy outcome studies. American Psychologist, 1977, 32, 752-760.

Stouffer, S. A. The American soldier (Vol. 1): Adjustment during Army life. Princeton, N.J: Princeton University Press, 1949.

(Accepted for publication October 26, 1982.) 